\title{
An etiological study of respiratory distress in neonates in a tertiary care medical college hospital
}

\author{
Harshini B.P. ${ }^{1}$, Kumar T.S. A. ${ }^{2 *}$, Kumar G. ${ }^{3}$, Khan I. ${ }^{4}$ \\ DOI: https://doi.org/10.17511/ijpr.2020.i01.04 \\ 1 Harshini B.P., Post Graduate Student, Department of Pediatrics, Sri Siddhartha Medical College, Sri Siddhartha Academy of Higher \\ Education, Tumakuru, Karnataka, India. \\ 2* Ananda Kumar T.S., Professor, Department of Paediatrics, Sri Siddhartha Medical College, Sri Siddhartha Academy of Higher Education, \\ Tumakuru, Karnataka, India. \\ 3 G.V. Kumar, Professor, Department of Paediatrics, Sri Siddhartha Medical College, Sri Siddhartha Academy of Higher Education, Tumakuru, \\ Karnataka, India. \\ 4 Imthyas Khan, V.H, Post Graduate Student of Paediatrics, Department of Paediatrics, Sri Siddhartha Medical College, Sri Siddhartha \\ Academy of Higher Education, Tumakuru, Karnataka, India.
}

Introduction: Respiratory distress is the most common cause of NICU admissions in newborns. Early diagnosis of cause of respiratory distress is important in the management of neonatal distress for better outcome. The high incidence of maternal risk factors and newborn receiving poor antenatal care continues to test the abilities of the neonatologist. Inspite of recent advance in clinching diagnosis and management there are very less clinical studies on the neonatal respiratory distress in our country. Materials and methods: A descriptive study of 150 neonates admitted to NICU of Sri Siddhartha Medical College and Hospital with clinical features suggestive of respiratory distress. All the newborn babies who developed respiratory distress within 72 hours of life were included in the study and those who developed respiratory distress after 72 hours of life was excluded from the study. Results: The commonest cause of neonatal respiratory distress in the present study was Respiratory distress syndrome (34\%), followed by Transient tachypnoea of the newborn (30\%), and Meconium aspiration syndrome (22.66\%). LSCS was most common mode of delivery. Conclusion: The most common causes of respiratory distress were RDS, TTNB, MAS, and birth asphyxia. Proper antenatal care and early diagnosis of the antenatal complication and avoiding preterm deliveries will aid in the better outcome of the newborns. Early detection and appropriate management are essential to ensure better outcome in all infants presenting with respiratory distress.

Keywords: Newborn, Respiratory Distress, Risk Factors, Respiratory distress syndrome, RDS

Corresponding Author

Ananda Kumar T.S., Professor, Department of Paediatrics, Sri Siddhartha Medical College, Sri Siddhartha Academy of Higher Education, Tumakuru, Karnataka, India.

Email: drtsanandkumar@gmail.com
How to Cite this Article

To Browse

Harshini BP, Ananda Kumar TS, Kumar GV, Khan I. An etiological study of respiratory distress in neonates in a tertiary care medical college hospital. Pediatric Rev Int J Pediatr Res. 2020;7(1):22-26. Available From https://pediatrics.medresearch.in/index.php/ijpr/arti cle/view/566

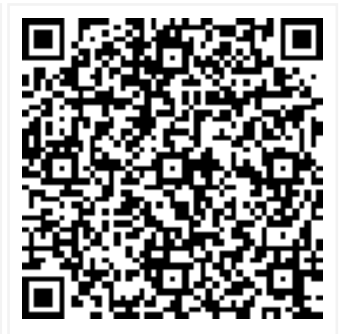

Manuscript Received 2020-01-10

Conflict of Interest No

Review Round 1
2020-01-20
Funding
Nil

Review Round 1 $\mathrm{Nil}$

Review Round 2
2020-01-26
Ethical Approval
Yes

Review Round 2 Yes
Review Round 3

Accepted 2020-01-30

Plagiarism $\mathbf{X}$-checker $8 \%$

(c) 2020 by Harshini B.P., Ananda Kumar T.S., G.V. Kumar, Imthyas Khan and Published by Siddharth Health Research and Social Welfare Society. This is an Open Access article licensed under a Creative Commons Attribution 4.0 International License https://creativecommons.org/licenses/by/4.0/ unported [CC BY 4.0]. 


\section{Introduction}

Respiratory difficulties constitute the commonest cause of morbidity in new-born. It is the most common cause of admission in a NICU. Early diagnosis of cause of respiratory distress is very important in the management of neonatal distress for better clinical outcome [1]. Respiratory distress is a symptom complex arising from disease processes that cause failure to maintain gaseous exchange [2]. The first breath and first cry have always been the mystical signalling the beginning of a new life. A variety of disorders of respiratory system like Transient tachypnea of the newborn, Hyaline membrane disease, Meconium aspiration syndrome, Pneumonia, Septicemia, Persistent pulmonary hypertension and non-respiratory disorders like intracranial injury, cardiac failure, metabolic disorders, septicemia and congenital malformations can manifest clinically with respiratory distress. $[2,3]$.

Definition Respiratory Distress is diagnosed clinically by the presence of at least two of the following criteria: Respiratory rate of $>60 /$ minute, Retractions (sub costal, xiphoid and suprasternal recession), Flaring of the alae nasi, Expiratory grunt and Cyanosis at room air on two consecutive examinations at least 1 hour apart [4]. There are various factors which determine the progress and outcome in neonatal respiratory distress. The birth weight, gestational age and the degree of respiratory compromise are the key factors which decide the level of care the neonate would require [5]. There has been a tremendous advance in the management of respiratory distress such as ventilator therapy with different modes such as CPAP, conventional mechanical ventilation; ultrahigh frequency jet ventilation, liquid ventilation, surfactant replacement therapy, sophisticated monitoring and extracorporeal membrane oxygenation all have improved the outcome among the babies with respiratory distress [6]. Nonetheless, the continued high incidence of maternal risk factors and newborn receiving poor antenatal care continues to test the abilities of the neonatologist [7]. Inspite of the varying recent advance in clinching diagnosis and management there has been very less clinical studies on the neonatal respiratory distress in our country. Therefore, there is a need to know the etiological factors and outcome of the babies with respiratory distress.

\section{Materials and Methods}

Study design: A descriptive study for a period of One year (2018-2019)

Study participants: Neonates admitted with signs of respiratory distress.

Study setting: NICU of Sri Siddhartha Medical College and Hospital

Inclusion criteria: All new-borns admitted to NICU of Sri Siddhartha medical College, within 72 hrs of birth due to respiratory distress.

Exclusion criteria: All new-borns admitted to NICU Sri Siddhartha Medical College and Hospital with onset of respiratory distress after $72 \mathrm{hrs}$.

Method of data collection: All the newborns enrolled in the study had their clinical and the demographic information recorded based on a prestructured proforma, weight of neonates was recorded by electronic weighing machine, the maturity was assessed based on new Ballard's score, the distress was assessed based on downe's score. The relative investigations were done and treatment as per unit protocol was followed. All neonates were examined daily till discharge from hospital or death. Mortality was documented to assess the clinical outcome against the final diagnosis.

Statistical analysis: All the data were tabulated in Microsoft Excel and Statistical analysis was done using SPSS program (version23), data was tabulated and comparison of proportions were performed using appropriate test, P-value of $<0.05$ was considered as statistically significant.

Ethical clearance was obtained from the institution.

Consent: Informed consent was obtained from parents of all the babies enrolled in the study.

\section{Results}

Among the 810 newborn delivered during the study period, $512(63.2 \%)$ newborn were admitted to NICU, 150 of them developed respiratory distress comprising $30.73 \%$ of all NICU admissions and with a frequency of $18.51 \%$.

Out of 150 newborns studied, it was seen that 135 $(90 \%)$ of the cases were of respiratory origin and $15(10 \%)$ were of non-respiratory in origin. 
Severity based on Downe's score 74 babies had moderate to severe respiratory distress and 8 had impending respiratory failure, i.e., 3 of TTNB, 4 of RDS, 1 of MAS, and 2 cases of congenital diaphragmatic hernia cases developed impending respiratory distress. Male predominance was seen and severity of respiratory distress was more in male babies compared to female babies. In the present study majority of the Term babies had TTNB
(82.2\%) followed by MAS $(61.8 \%)$ and in late preterms RDS $(60 \%)$ was most commonly seen. (Table $1)$.

Threatened scar rupture was the most common indication for LSCS with $41 \%$ of the total cases developing respiratory distress. $62 \%$ of the babies with MAS were born with meconium stained amniotic fluid. Maternal hypertension was seen in $36 \%$ of the total cases (Table 2 ).

Table-1: Fetal factors associated with respiratory distress in neonates.

\begin{tabular}{|c|c|c|c|c|c|}
\hline \multicolumn{2}{|c|}{$\begin{array}{l}\text { Neonatal and maternal } \\
\text { characteristics }\end{array}$} & $\begin{array}{l}\text { Transient tachypnea of the } \\
\text { newborn }\end{array}$ & $\begin{array}{l}\text { Respiratory distress } \\
\text { syndrome }\end{array}$ & $\begin{array}{l}\text { Meconium aspiration } \\
\text { syndrome }\end{array}$ & $\begin{array}{c}\text { Birth } \\
\text { asphyxia }\end{array}$ \\
\hline \multirow[t]{3}{*}{ Period of gestation } & Term & $37(82.2 \%)$ & $1(2 \%)$ & $21(61.8 \%)$ & $5(83.3 \%)$ \\
\hline & Late preterm & $8(17.8 \%)$ & $30(60 \%)$ & $11(32.3 \%)$ & $1(16.7 \%)$ \\
\hline & Early preterm & $0(0 \%)$ & $19(38 \%)$ & $2(5.9 \%)$ & $0(0 \%)$ \\
\hline \multirow[t]{4}{*}{ Birth weight } & NBW & $27(60 \%)$ & $6(12 \%)$ & $23(67.7 \%)$ & $5(83.3 \%)$ \\
\hline & LBW & $18(40 \%)$ & 35 (70\%) & $9(26.3 \%)$ & $1(17.7 \%)$ \\
\hline & VLBW & $0(0 \%)$ & $7(14 \%)$ & $1(3 \%)$ & $0(0 \%)$ \\
\hline & ELBW & $0(0 \%)$ & $2(4 \%)$ & $1(3 \%)$ & $0(0 \%)$ \\
\hline \multicolumn{2}{|l|}{$\operatorname{Sex}(M / F)$} & $23 / 22$ & $30 / 20$ & $18 / 17$ & $1 / 5$ \\
\hline
\end{tabular}

Table-2: Maternal Factors associated with respiratory distress in neonates

\begin{tabular}{|l|l|l|l|l|}
\hline Maternal risk factors (\%) & \multicolumn{1}{|c|}{$\begin{array}{c}\text { Transient tachypnea of the } \\
\text { newborn }\end{array}$} & \multicolumn{1}{|c|}{$\begin{array}{c}\text { Respiratory distress } \\
\text { syndrome }\end{array}$} & \multicolumn{1}{|c|}{$\begin{array}{c}\text { Meconium aspiration } \\
\text { syndrome }\end{array}$} & \begin{tabular}{l} 
Birth asphyxia \\
\hline Premature rupture of membrane
\end{tabular} \\
\hline Hypertension & $4(6.7 \%)$ & $3(6 \%)$ & $0(0 \%)$ & $0(0 \%)$ \\
\hline Diabetes Mellitus & $2(4.4 \%)$ & $12(24 \%)$ & $1(3 \%)$ & $0(0 \%)$ \\
\hline Threatened Scar Rupture & $6(13.3 \%)$ & $0(0 \%)$ & $0(0 \%)$ & $0(0 \%)$ \\
\hline $\begin{array}{l}\text { Meconium Stained Amniotic } \\
\text { Fluid }\end{array}$ & $0(0 \%)$ & $11(22 \%)$ & $2(6 \%)$ & $0(0 \%)$ \\
\hline
\end{tabular}

Table-3: Type of delivery associated with respiratory distress in neonates.

\begin{tabular}{|l|l|l|l|}
\hline \multirow{2}{*}{ Diagnosis } & \multicolumn{3}{|c|}{ Type of delivery } \\
\cline { 2 - 4 } & Normal & $\begin{array}{l}\text { Elective } \\
\text { LSCS }\end{array}$ & $\begin{array}{l}\text { Emergency } \\
\text { LSCS }\end{array}$ \\
\hline $\begin{array}{l}\text { Transient tachypnea of the } \\
\text { newborn }\end{array}$ & $12(26.7)$ & $3(6.7 \%)$ & $30(66.7 \%)$ \\
\hline Meconium aspiration syndrome & $8(23.5 \%)$ & $6(17.6 \%)$ & $20(58.8 \%)$ \\
\hline Respiratory distress syndrome & 13 & $4(8.0 \%)$ & $33(66.0 \%)$ \\
\hline Birth asphyxia & $(26.0 \%)$ & & \\
\hline Pneumonia & $1(16.7 \%)$ & $0(0 \%)$ & $5(83.3 \%)$ \\
\hline
\end{tabular}

LSCS was most common mode of delivery in the present study, comprising 113 of the deliveries. Majority of the TTNB, RDS, MAS cases were delivered through LSCS (Table 3). The study comprised of 93 babies born to mothers in the age group 18-25 years 61 (66.3\%) of them developed moderate to severe respiratory distress.
Out of 57 babies both in maternal age group 26-33 years, $31(33.7 \%)$ of them developed moderate to severe respiratory distress. Primigravida mothers were predominant in the present study.

There were 7 deaths in the study. Overall outcome of Neonatal Respiratory Distress was cure in $90 \%$, Neonatal mortality rate of $4.66 \%$, and maximum mortality was seen in cases with Respiratory Distress Syndrome.

\section{Discussion}

Neonates with respiratory distress are 2 to 4 times more likely to die than those without respiratory distress [8]. Frequency of respiratory distress in the present study was $18.51 \%$ whereas in study done by Swarnakar Et al, it was $2.83 \%$ [9]. Out of 150 neonates the most common cause of neonatal respiratory distress in the present study was 
Respiratory distress syndrome (34\%), Transient tachypnea of the newborn (30\%), and Meconium aspiration syndrome (22.66\%).

In study done by Kommawar et al., the most common cause of neonatal respiratory distress was TTN 160 (40\%) followed by 107 (26.75\%) respiratory distress syndrome and birth asphyxia was seen in $49 \quad(12.25 \%)$ babies.[10] Chandrashekar et al., studied that the commonest cause for respiratory distress was Transient tachypnea of Newborn (60\%) followed by Meconium Aspiration Syndrome (31\%) and RDS (6\%) in their study [3]. (Table 4) showing comparison of the current study results with other studies.

Table-4: Comparison of Respiratory distress with other studies

\begin{tabular}{|l|l|l|l|l|}
\hline & $\begin{array}{r}\text { Swarnakar } \\
\text { et al., [9] }\end{array}$ & $\begin{array}{c}\text { Santosh S et } \\
\text { al., [18] }\end{array}$ & $\begin{array}{r}\text { Kommawar } \\
\text { et al., [10] }\end{array}$ & $\begin{array}{r}\text { Current } \\
\text { study }\end{array}$ \\
\hline $\begin{array}{l}\text { Respiratory distress } \\
\text { syndrome }\end{array}$ & $24(17.14 \%)$ & $24(31.5 \%)$ & $107(26.75 \%)$ & $50(34 \%)$ \\
\hline $\begin{array}{l}\text { Transient tachypnea } \\
\text { of the newborn }\end{array}$ & $57(40.7 \%)$ & $35(46 \%)$ & $160(40 \%)$ & $45(30 \%)$ \\
\hline $\begin{array}{l}\text { Meconium aspiration } \\
\text { syndrome }\end{array}$ & $13(9.28 \%)$ & $6(7.8 \%)$ & $(15 \%)$ & $\begin{array}{l}33(22.66 \\
\%)\end{array}$ \\
\hline Birth ashyxia & $16(11.42 \%)$ & $19(25 \%)$ & $49(12.25 \%)$ & $6(4 \%)$ \\
\hline pneumonia & $11(7.85 \%)$ & $19(25 \%)$ & & $3(2 \%)$ \\
\hline
\end{tabular}

In the present study, out of 150 neonates 113 (75\%) were born through LSCS. Among them 33 (74\%) born through LSCS developed TTNB, 26 (77\%) developed MAS, 37 (74\%) developed RDS. Similar results were seen in study done by Swarnakar et al.,[9] where majority of cases of TTNB (52.6\%) and RDS (66.7\%) were delivered by elective caesarean section. According to Tudehope et al TTNB is the commonest cause of RD accounting for $41 \%$, he also showed TTNB was more common following caesarean section than the normal vaginal delivery. [11].

In the present study, it was observed that 83 babies were born to primigravida mothers and 51 (57.3\%) of them developed moderate to severe respiratory distress and $38(42.7 \%)$ babies born to 67 multigravida mothers developed moderate to severe respiratory distress. In study by Brahmaiah et al., there were primigravida $(56.5 \%)$, second gravida $(35.5 \%)$, and multi gravida $(8 \%)$. There is increased risk of respiratory distress in primigravida probably due to prolonged delivery. Similar results were obtained in a study conducted by C Dani. Et al [12] and Chandrashekar et al., [3].
In the present study, out of 93 babies born to mothers in the age group 18-25 years 61 (66.3\%) of them developed moderate to severe respiratory distress and out of 57 babies born in maternal age group 26-33 years, 31 (33.7\%) of them developed moderate to severe respiratory distress. In the Brahmaiah et al., [2] study only $2 \%$ of mothers belong to age group above 30 years whose babies had severe Respiratory Distress which was found to be a risk factor. Similar results were seen with the studies by C Dani [12] and Alwyn Smith [13].

In the present study, $59 \%$ of the babies in the study were normal birth weight, 35\% were low birth weight, $5 \%$ were very low birth weight and $1 \%$ were extremely low birth weight. In the Brahmaiah et al.,[2] study the birth weight of $<2.5 \mathrm{~kg}$ were $59 \%, 2.5-4 \mathrm{~kg}$ were $40 \%$ and $>4 \mathrm{~kg}$ were $1 \%$, severe RD was observed in $<2.5 \mathrm{~kg}$ (41.4\%). These results were in accordance with studies done by $M$ Lureti et al [14], Kwang Sunlee et a [15], C Dani et al [12], Chandrashekar et al [3] and Brahmaiah et al.,[2] where increased Respiratory Distress was observed with decrease in birth weight especially of $<2.5 \mathrm{~kg}$.

In the present study, it was observed that a majority of term babies in TTNB (82.8\%) and MAS $(61.8 \%)$ followed by late preterm $(60 \%)$ in RDS. Birth asphyxia was seen mostly term babies. Incidence of TTNB was higher in late preterm and term babies in Brahmaiah et al study [2] and similar results were seen in study done by Jain et al [17]. Brahmaiah et al [2] also observed that in their study incidence of MAS was high in more than 37weeks.

In the present study, it was observed that threatened scar rupture was the most common indication for emergency LSCS (55.55\%), followed by fetal distress $(23.23 \%)$, pre-ecclampsia (22.22\%) and MSAF (20.20\%). Most common risk factor for TTNB was threatened scar rupture $(13.3 \%)$ was found in the present study. Maternal hypertension (28\%) was most common risk factor for developing RDS. 21 (62\%) babies has meconium staining of amniotic fluid that developed meconium aspiration syndrome. Brahmaiah et al [2] observed in their study that HTN was mostly associated with TTNB (17.4\%), MAS (17.4\%), Birth asphyxia $(17.4 \%)$, and Sepsis (17.4\%). GDM was most commonly associated with development of TTNB. Oligohydramnios most commonly associated with TTNB (54.5\%) followed by Pneumonia (36.4\%) and HMD (9.1\%). PROM was significantly associated with pneumonia (50\%), and HMD (50\%). 
Chandrashekar et al [3] studied that $68.4 \%$ of newborns (26 out of 38) born to mothers with meconium stained liquor developed severe respiratory distress when compared to $35.40 \%$ of the new-borns (22 out of 62) born to mother who had clear liquor.

In the present study, there were 7 deaths. Cure rate of Neonatal Respiratory Distress was 90\%, with Neonatal mortality rate of $4.66 \%$, and a maximum mortality of $12 \%$ in Respiratory Distress Syndrome cases. Majority of the deaths were seen in male babies. Santosh S Et al.,[18] studied that $92.2 \%$ of the cases survived with 6 deaths. 4 deaths were due to prematurity with RDS, 1 due to preterm with $B A$ with RDS and 1 due to BA with RDS and sepsis. Majority of the deaths were due to RDS (83\%). Our results are in accordance with study done by Brahmaiah et al.,[2] they noted mortality of $17 \%$ and deaths are due to Hyaline membrane disease $(47 \%)$, Septicaemia (23\%), Severe birth asphyxia $(12 \%)$, Pulmonary haemorrhage $(12 \%)$ and CHD $(6 \%)$.

Limitations of the study: The present study was conducted on 150 neonates in a tertiary care hospital. Most of them were referred cases from peripheral hospitals. The same study should be done in community based setting with more samples in multicentre and the meta-analysis of the results will give clear spectrum of respiratory distress in our community.

\section{Conclusion}

Respiratory distress syndrome was found to be the most common causes of respiratory distress and NICU admission in newborns in the present study which was followed by transient tachypnea of the newborn, meconium aspiration syndrome and birth asphyxia. Caesarean section was the associated risk factor in developing respiratory distress in most of the neonates. Maternal hypertension and threatened scar rupture was the most common associated maternal risk factor in the study.

Fetal risk factors were low birth weight and late preterm period of gestation. Proper antenatal care and early diagnosis of the antenatal complication and avoiding preterm deliveries will aid in the better outcome of the newborns. Early detection and appropriate management of the condition is essential to ensure better outcome in all infants presenting with respiratory distress.

\section{What this study adds to the existing knowledge?}

Respiratory distress syndrome is the increasing cause of neonatal morbidity and mortality in developing country and its increasing frequency in late preterm babies prompt for more studies in late preterm babies.

\section{Author's Contribution}

Dr. Harshini BP: Data collection and statistical analysis

Dr. TS Ananda Kumar: Study design and study format and manuscript review

Dr. Kumar GV and Dr. Imthyas Khan: Manuscript preparation

\section{Reference}

01. Bajad M, Goyal S, Jain B. Clinical profile of neonates with respiratory distress. Int J Contemp Pediatr. 2016;3(3)1009-1003. doi: 10.18203/2349$3291 . i j c p 20162382 \quad$ [Crossref][PubMed][Google Scholar]

02. Brahmaiah P, Reddy KR. Etiological Study of respiratory distress in newborn. Int J Contemp Med Res. 2017;4(10)2202-2206. [Crossref][PubMed] [Google Scholar]

03. Chandrasekhar R, Mohan MM, Lakshmi BV. Clinical study of respiratory distress in newborn. Int J Contemp Pediatr. 2016;10;2349-3291. doi: 10.18203/2349-3291.ijcp20162364 [Crossref] [PubMed][Google Scholar]

04. Guha D. NNF Recommended basic perinatalneonatal nomenclature. Neonatology-Principles and Practice. 1998;1;131-132. [Crossref][PubMed] [Google Scholar]

05. John BM, Venkateshwar V, Dagar V. Predictors of Outcome in Neonates with Respiratory Distress. J Nepal Paediatr Soc. 2015;35(1)31-37. doi: [Article] [Crossref][PubMed][Google Scholar]

06. Rao GC, Rao MS. Etiological profile of respiratory distress in first day of life of a newborn baby. Int J Contemp Pediatr. 2017;4(1)210-214. doi: 10.18203/2349-3291.ijcp20164606 [Crossref] [PubMed][Google Scholar] 
07. Amarendra M, Rama G, Kiran CR, Raju DV. Aetiology of respiratory distress and risk factors associated with development of respiratory distress in term newborns. Hernia. 2017;1(1)100. doi: $10.18410 / \mathrm{jebmh} / 2017 / 163 \quad$ [Crossref][PubMed] [Google Scholar]

08. Misra PK. Respiratory distress in newborn- A prospective study. Indian pediatrics. 1987;24(1)7780. [Crossref][PubMed][Google Scholar]

09. Swarnkar K, Swarnkar M. Neonatal respiratory distress in early neonatal period and its outcome. Int J Biomed Adv Res. 2015;6(09)643-647. doi: 10.7439/ijbar [Crossref][PubMed][Google Scholar]

10. Kommawar A, Borkar R, Vagha J, Lakhkar B, Meshram R, Taksandae A. Study of respiratory distress in newborn. Int $\mathrm{J}$ Contemp Pediatr. 2017;4(2)490-494. doi: [Article][Crossref][PubMed] [Google Scholar]

11. Tudehope DI, Smyth MH. Is transient tachypnoea of the newborn" always a benign disease?- Report of 6 babies requiring mechanical ventilation. Aust Paediatr J. 1979;15(3)160-165. doi: $\quad 10.1111 / j .1440-1754.1979 . t b 01215 . x$ [Crossref][PubMed][Google Scholar]

12. Dani C, Reali MF, Bertini G, Wiechmann L, Spagnolo A, Tangucci $M$, et al. Risk factors for the development of respiratory distress syndrome and transient tachypnoea in newborn infants. Italian Group of Neonatal Pneumology. Europe Resp J. 1999;14(1)155-159 [Crossref][PubMed][Google Scholar]
13. Malhotra AK, Nagpal R, Gupta RK, Chhajta DS, Arora RK. Respiratory distress in newborn: treated with ventilation in a level II nursery. Indian Pediatr. 1995;32;207-207. [Crossref][PubMed][Google Scholar]

14. Luerti M, Parazzini F, Agarossi A, Bianchi C, Rocchetti $M$, Bevilacqua $G$. Risk factors for respiratory distress syndrome in the newborn- a multicenter Italian survey. Acta Obstetricia et Gynecologica Scand. 1993;72(5)359-364. doi: 10.3109/00016349309021113 [Crossref][PubMed] [Google Scholar]

15. Lee KS, Eidelman AI, Tseng PI, Kandail SR, Gartner LM. Respiratory distress syndrome of the newborn and complications of pregnancy. Pediatr. 1976;58(5)675-80. [Crossref][PubMed][Google Scholar]

16. Jain L, Dudell GG. Respiratory transition in infants delivered by cesarean section. Seminars in Perinatol. 2006;30(5)296-304. doi: 10.1053/j.semperi.2006.07.011 [Crossref][PubMed] [Google Scholar]

17. Santosh S, Kushal KK, Adarsha E. A clinical study of respiratory distress in newborn and its outcome. Indian J Neonatal Med Res. 2013;1(1)2-4. [Crossref][PubMed][Google Scholar] 